\title{
A EXPERIÊNCIA VIVIDA POR PESSOAS COM TUMOR CEREBRAL E POR SEUS FAMILIARES
}

\section{The Experience of Brain Tumor Patients and their Family Members}

\author{
Danilo Saretta Verissimo ${ }^{1}$ \\ Elizabeth Ranier Martins do Valle ${ }^{2}$
}

\section{Resumo}

O presente artigo constitui o relato de uma pesquisa cujo objetivo foi investigar a experiência vivida por pessoas com tumor cerebral e por seus familiares. Para tanto, partiu-se da assistência psicossocial oferecida em grupos de sala de espera no Ambulatório de Neurocirurgia Oncológica do Hospital das Clínicas da Faculdade de Medicina de Ribeirão Preto - USP. Sete sessões de grupo foram gravadas, transcritas e analisadas. Na investigação, orientou-se por uma perspectiva qualitativa em psicologia fundamentada na fenomenologia, particularmente, na obra de Maurice Merleau-Ponty. Na compreensão dos relatos analisados, duas questões ganharam evidência. Primeiramente, a de que a experiência do adoecimento para os pacientes é marcada pelo sentido de que a vida presente é muito diferente da de outrora. Há como que um choque entre o eu-corpo atual e o eu-corpo passado. Em segundo lugar, é notável a restrição pessoal que marca esta experiência do enfermo. Tal restrição revela-se nas perturbações da motricidade; nos temores e angústias que o assaltam; nas relações estabelecidas em família, marcadas por uma superproteção que cerceia e pela dependência em relação aos cuidados do outro; e nas experiências com o meio social extrafamiliar que despertam vergonha e o ímpeto de se isolar. Quanto aos familiares, vivenciam uma intensa carga de preocupações e temores que os levam a uma atitude, por vezes, superprotetora.

Palavras-chave: Tumor cerebral; Grupo de sala de espera; Maurice Merleau-Ponty.

\section{Abstract}

This article reports on a study aimed at examining the experience of brain tumor patients and their family members, based on psychosocial care offered in waiting room groups at the Oncologic Neurosurgery Clinic of the University of São Paulo at Ribeirão Preto Medical School Hospital das Clínicas. We recorded, transcribed and analyzed seven group sessions. This research was guided by a qualitative perspective based on phenomenological psychology, particularly the work of Maurice Merleau-Ponty. In understanding the analyzed reports, two issues stood out. Firstly, for the patients, and definitely for the family members, the sickening experience is marked by the sense that the current life is very different from the past. There is as if itwere a shock between the I-currentbody and the I-pastbody. Secondly, the patient's experience is marked by a noticeable personal restriction. This restriction appears in movement disturbances; in the fears and anguish the patient is attacked by; in the family relations that are established, marked by a limiting overprotection and by the dependence in relation to otherpersons' care; and in the experiences with the extrafamily so cial environment, which arouse shame and the urge to get isolated. As to family members, they bear an intense burden of preoccupations and fears that lead to a sometimes overprotective attitude.

Keywords: Brain tumor; Waiting room group; Maurice Merleau-Ponty

1 Psicólogo do Serviço de Oncologia do Hospital das Clínicas da Faculdade de Medicina de Ribeirão Preto - USP, Mestre em Psicologia pela Universidade de São Paulo.

2 Professora Livre-docente aposentada da Escola de Enfermagem de Ribeirão Preto-USP. Endereço: Avenida dos Bandeirantes, 3900, CEP 14040-902, EERP-USP, Ribeirão Preto, São Paulo, Email: bethvale@eerp.usp.br. 


\section{Introdução}

Neste artigo, apresenta-se uma pesquisa em que se buscou realizar uma aproximação compreensiva às experiências vividas por portadores de tumor cerebral e pelos seus familiares (Verissimo, 2005). Os colaboradores deste trabalho freqüentaram sessões de grupo de sala de espera no Ambulatório de Neurocinurgia Oncológica do Hospital das Clínicas da Faculdade de Medicina de Ribeirão Preto - USP (HCFMRP - USP), situação na qual se obteve acesso aos relatos de suas vivências.

Os tumores primários do sistema nervoso central representam cerca de $5 \%$ das neoplasias e sua incidência é de 6 a 12 casos a cada 100.000 habitantes por ano. Existem vários tipos de tumores cerebrais, alguns com alta porcentagem de cura, outros extremamente agressivos. Comumente, 0 tratamento envolve cirurgia, quimioterapia e radioterapia, isoladamente ou de maneira combinada (Brada, 1999).

Somando-se os efeitos deletérios da doença aos efeitos colaterais do tratamento, o paciente com tumor cerebral pode conviver com severos sintomas físicos e neuropsiquiátricos. São comuns os déficits motores, as crises epilépticas e as alterações visuais. Mas a prevalência é mesmo das desordens mentais orgânicas (Passik, 1994). As funções cognitivas são as mais afetadas (Weitzner; Meyers \& Byrne, 1996), tais como memória, inteligência, aprendizagem, linguagem e atenção. Pode haver, ainda, perturbação na percepção, no conteúdo do pensamento, no humor, nas emoções e no padrão global de personalidade e comportamento.

Lepola (2001), bem como Fox e Lantz (1998), considera escassa a quantidade de estudos que tenham focalizado as vivências relacionadas ao adoecimento por tumor cerebral, sobretudo em uma perspectiva descritiva. Leavitt, Lamb e Voss (1996) realizaram encontros em grupos de apoio com portadores de tumor cerebral e seus familiares e, até o ano de publicação do estudo, não encontraram qualquer descrição de trabalho semelhante. De qualquer forma, na literatura estudada, a experiência do câncer neurológico é descrita como única entre as situações oncológicas. Esta unicidade tem relação com as perdas sofridas pelos pacientes nas funções indicadas anteriormente, além das conseqüentes alterações sociais e psicológicas que vivenciam.
O período do diagnóstico está relacionado a mudanças drásticas e repentinas para o portador de um tumor cerebral. É um momento marcado por medo, desorganização, confusão e dúvidas, em que, freqüentemente, as decisões são tomadas em um clima de urgência (Leavitt et al., 1996). O enfermo precisa enfrentar ainda as expectativas para a cirurgia cerebral, quase sempre indicada. Segundo Lepola (2001), os pacientes demonstram elevada preocupação com os déficits que podem surgir após a operação. Essencialmente, expressam temor diante do risco de alterações na esfera mental.

Ainda conforme as descrições de Lepola (2001), o momento que segue à cirurgia é marcado pelas vivências iniciais das alterações na imagem corporal, pela necessidade de recuperação e por preocupações com o futuro. Também, é evidente o choque dos pacientes diante do déficit de linguagem, da hemiplegia e de outros sintomas, principalmente se não tiverem sido preparados para tais efeitos. Além disso, após a cirurgia, muitos pacientes demonstram a disposição para a reconsideração dos seus valores vitais. Mostram, sobremaneira, o desejo de movimentar-se com autonomia e de retornar ao trabalho o quanto antes. Ao mesmo tempo, angustiam-se com a possibilidade de recorrência do tumor.

A fase crônica da enfermidade envolve 0 período de tratamento e de seguimento ao paciente. Fox e Lantz (1998) observaram que, no convívio com a doença, os portadores de tumor cerebral sinalizam o enfrentamento de um estigma social ligado à enfermidade neurológica, o que acarreta profundos sentimentos de humilhação, discriminação e isolamento social. Dizem enfrentar uma doença que lhes ataca o corpo e a mente e que leva ao desmantelamento da identidade pessoal, fato de caráter fortemente desestruturador. Assim, dizem os autores, para os pacientes, torna-se ainda mais difícil a tarefa de integrar a condição pessoal anterior à enfermidade com a atual. Os autores perceberam o empenho dos enfermos para manter algum nível de normalidade nos âmbitos social e do trabalho e compreenderam tratar-se de uma maneira de preservar um senso de competência que resguarda, também, a noção de "eu".

Wideheim, Edvardsson, Pahlson e Ahlström (2002) destacaram um outro sentido para o empenho dos pacientes nas tarefas cotidianas. Em virtude dos déficits funcionais, os portadores de 
tumor cerebral vivenciam limitações severas e, com isso, adquirem um grau elevado de dependência dos seus cuidadores. Ao realizarem tarefas em sintonia com a sua habilidade e energia, esperam diminuir este senso de dependência e experimentar algum sentido no cotidiano. Segundo os autores, os pacientes esforçam-se, principalmente, para desempenhar antigos papéis.

A dificuldade para se comunicar também é motivo de contrariedade para o paciente. Por vezes, a comunicação com as pessoas próximas é árdua e até mesmo pedir ajuda torna-se difícil. Dessa forma, surgem a vergonha, o embaraço e a confusão. Por isso, freqüentemente o enfermo isola-se e rompe os seus laços sociais, sentindo-se um fardo para aqueles que estão ao seu redor (Leavitt et al., 1996; Passik, 1994).

Quanto à fase do desfecho do tratamento, a literatura obtida não trouxe informações específicas sobre a vivência dos portadores de tumor cerebral.

Em relação ao impacto psicossocial sobre as famílias dos portadores de tumor cerebral, a literatura destaca, sobretudo, as alterações nos papéis familiares e a sobrecarga vivenciada pelos cuidadores (Foz \& Lantz, 1998). Estes se vêem na posse de novas responsabilidades, algumas completamente estranhas ao papel anterior que tinham na organização familiar. Além disso, há o acúmulo de deveres. Os entes próximos lidam, também, com a preocupação de preservar os desejos e capacidades do enfermo, resguardando a auto-estima.

Outro motivo de desgaste e culpa é a lida com as alterações de personalidade e de humor que podem acometer os enfermos (Leavitt at al, 1996). Quanto à decadência das capacidades cognitivas do paciente, Weitzner e Meyers (1997 apud Wideheim etal., 2002) ${ }^{3}$ comentam que ela dificulta ou impede que, no caso do adoecimento de um dos cônjuges, o casal enfrente conjuntamente as tristezas, as perdas e as ansiedades relativas ao futuro.

A família enfrenta diariamente outras constantes ansiedades, entre elas, o medo de perder 0 ente querido, o convívio com as suas alterações corporais, que a todo instante revelam a presença da enfermidade, o fato de assistir ao declínio físico e mental do doente, as dificuldades financeiras, 0 isolamento social. Por outro lado, quando um coti- diano mais próximo do normal é possível, os familiares podem exercer atividades com alguma importância e sentido pessoais, o que gera algum sentimento de segurança, de confiança, de esperança e de autocuidado. Este bem-estar, certamente, encontra reflexos na sua capacidade para atender às demandas do enfermo (Wideheim et al., 2002).

Wideheim et al. (2002) destacaram, também, o papel protetor que, em família, uns exercem em relação aos outros. Fala-se em viver o presente e evitar falar no futuro. Neste contexto, Giovagnoli (1999) menciona a atitude freqüente entre os familiares de proteger os pacientes da realidade, sobretudo em relação ao prognóstico da doença.

\section{Os Grupos de Sala de Espera}

Os tratamentos psicológicos podem amenizar o sofrimento e melhorar a qualidade de vida dos pacientes acometidos pelo câncer e de seus familiares (Harvard College, 2003). Intervenções em grupo ou individuais podem facilitar 0 conhecimento e manejo de informações, a expressão e elaboração das emoções relacionadas à doença, o reforço do suporte familiar e social, além de melhorar o contato com a equipe de saúde (Spiegel \& Diamond, 1998).

No presente estudo, a experiência comunicada dos portadores de tumor cerebral e dos seus familiares foi obtida na situação de encontros em grupos de sala de espera. Na literatura científica, o termo grupo de sala de espera é encontrado com alguma variação de significados. Neste trabalho, é compreendido como intervenção em grupo junto a pacientes ambulatoriais no instante em que aguardam por uma consulta médica ou qualquer outro procedimento em saúde. Trata-se de uma intervenção psicoterapêutica de suporte, segundo a classificação proposta por Campos (1992). Os grupos de sala de espera configuram uma estratégia de atuação dentre as práticas grupais em psicologia, constituindo uma forma de encontro entre os profissionais da saúde e os pacientes e seus familiares em diversos contextos.

Os grupos de sala de espera assentam-se sobre os objetivos basilares de oferecer apoio emocional e esclarecer, para os usuários de servi-

3 WEITZNER, M. A. \& MEYERS, C. A. (1997) Cognitive functioning and quality of life in malignant glioma patients: a review of the literature. Psycho-oncology, v. 6, p. 169-177. 
ços de saúde diversos, algumas questões médicas. Fala-se na construção de espaços de conversação, reflexão e troca de experiências entre os usuários (Moreira, 2001) e destaca-se 0 ato de "conversar junto" enquanto processo potencialmente fértil para construções polissêmicas sobre os temas em saúde. No encontro grupal, são criadas condições favoráveis para um processo de reconstrução dos sentidos atribuídos ao "eu" e a uma condição vital qualquer, como o envelhecimento ou uma enfermidade, por exemplo (Moreira \& Japur, 2003). Portanto, trata-se de favorecer o encontro entre pessoas vivenciando conflitos e ansiedades semelhantes mediado por profissionais da área da saúde, para, assim, poderem pensar formas de se viver melhor uma determinada situação (Domingues, 1992). O grupo de sala de espera também é caracterizado como uma forma produtiva de ocupar um espaço e tempo ociosos nas instituições, com a transformação do período de espera pelas consultas em momento de trabalho (Maldonado \& Hallal, 1981; Moreira., 2001; Souza, Fraga \& Braga, 2000). Trata-se de potencializar um espaço informal já existente na instituição, atendendo a pessoas que não apresentam uma demanda explícita por atendimento psicológico.

Quanto ao enquadre, os grupos de sala de espera comportam pouca estruturação. Normalmente, o encontro acontece na própria sala de espera, aproveitando-se o grupo espontaneamente formado no local. O grupo é aberto e com composição flutuante, podendo haver várias configurações em um mesmo encontro. Isto ocorre porque, enquanto novos pacientes chegam em um ambulatório para aguardar uma consulta médica, outros são chamados para ela, deixando o grupo. Além disso, segundo os estudos referidos, usualmente há heterogeneidade em relação à idade, sexo e nível de participação dos integrantes, mesclando-se pessoas com participações anteriores e novatos na atividade. A homogeneidade do grupo normalmente refere-se à condição vital ou enfermidade sob cuidado. O enfoque do grupo é no aquie-agora e a sessão deve possuir começo, meio e fim, visto que é única. Quanto à coordenação, comporta o trabalho interdisciplinar.

\section{Métodos}

No presente trabalho, adotou-se o pensamento fenomenológico como guia na aproximação à experiência vivida dos portadores de tumor cerebral e de seus familiares, colaboradores no estudo. Buscou-se sustentação, sobretudo, no pensamento do filósofo francês Maurice Merleau-Ponty. Longe de ser tomada como base metodológica, sua filosofia aparece como um pensar que favorece a elaboração e compreensão das experiências vividas, visto que oferece uma visão significativa acerca da experiência humana e da forma como podemos nos aproximar dela, respeitando o que lhe é essencial. Merleau-Ponty (1999) mostrou que o homem está sempre situado em relação ao ambiente e lhe empresta sentidos. Além disso, destacou o corpo como a sede privilegiada dessa apropriação do mundo.

Quanto ao trabalho compreensivo, seja nas ciências humanas, seja na filosofia, ganha contornos próprios na perspectiva fenomenológica. Ainda conforme Merleau-Ponty (1999), os fatos vivenciais não existem como objeto, como algo em terceira pessoa. A classe social, os afetos, a doença são antes vividos concretamente para, então, se tornarem objetos de uma vontade deliberada. Isso possui implicações no momento em que se deseja compreendê-los, visto que, para tanto, se deve buscá-los em seu estado de surgimento.

Assim, na prática científica, em uma perspectiva fenomenológica, importam a fidelidade ao fenômeno, a consideração dos materiais empregados e a proximidade da descrição. Merleau-Ponty (1990, p.21) escreveu: "[...] trata-se somente de tomar contato com os fatos, de compreendê-los em si mesmos, de lê-los e de decifrá-los de modo a lhes dar um sentido". O foco das pesquisas ancoradas na fenomenologia é a busca do sentido que permeia as manifestações do homem, tidas como fenômenos originais, simbólicos e polissêmicos, que comportam várias interpretações e que se beneficiam do seu conflito (Valle, 1997).

\section{Acesso a os Relatos da Ex periência Vivida}

Esta pesquisa foi realizada no Ambulatório de Neurocirurgia Oncológica do HCFMRP 
A experiência vivida por pessoas com tumor cerebral e por seus familiares

- USP. Neste serviço, um dos autores deste estudo coordenava, juntamente com uma assistente social, sessões de grupo de sala de espera com os usuários do ambulatório. Nele são acompanhados cerca de setenta pacientes com diferentes diagnósticos de tumor cerebral e em diferentes fases do tratamento. Os usuários são adultos, com faixa etária variada. A maioria é procedente de Ribeirão Preto e região, mas há os que vêm de distantes localidades do país. Parte dos pacientes encontra-se em seguimento clínico e por exames de imagem, sendo os retornos médicos bastante espaçados. Outra parte encontrase em tratamento ativo, passando por cirurgias, radioterapia ou quimioterapia.

Quanto às sessões de grupo de sala de espera, pacientes e acompanhantes eram convidados a participar, sendo lembrados de que a adesão era livre. Os grupos funcionavam, em média, com seis participantes entre pacientes e familiares. Os encontros duravam cerca de cinqüenta minutos e tinham lugar em uma sala de atendimento médico ${ }^{4}$.

Para constituir o material discursivo, foco do trabalho de compreensão da experiência vivida nesta pesquisa, realizou-se a gravação em áudio e a posterior transcrição integral de dez sessões de grupo de sala de espera. No entanto, apenas sete sessões foram utilizadas no processo de análise compreensiva. A definição das sessões a serem analisadas não seguiu outro critério além da impressão de que o material obtido apresentava várias perspectivas do fenômeno estudado, permitindo uma exploração suficientemente vasta dele. Conforme a natureza da intervenção de apoio, alguns colaboradores participaram em mais de um encontro, enquanto outros participaram uma única vez. Ao todo, treze pacientes e dez acompanhantes são colaboradores nesta pesquisa. Na tabela 1 encontram-se organizadas algumas informações básicas sobre os pacientes participantes. Os nomes utilizados são fictícios. Com isso, pretende-se proteger a identidade dos colaboradores sem, contudo, perder o senso de que se referem a pessoas concretas, com uma história e nome próprios.

\section{Procedimentos para a Análise Compreensiva dos Relatos}

O processo compreensivo envolveu, primeiramente, a leitura cuidadosa das transcrições das sessões de grupo para que se extraísse delas os aspectos que impressionavam o pesquisador dentro do campo perceptivo iluminado pela sua interrogação. Tais aspectos constituíram as unidades de significado. Como o contexto em que se teve acesso aos relatos dos colaboradores envolveu a construção de discursos em uma situação grupal, em vários momentos os recortes de trechos significativos abarcaram as mudanças de clima ao longo das sessões, focalizando, assim, o discurso coletivo, com suas tensões e riqueza de sentidos. Estes conjuntos de significados articulados, Detoni e Paulo (2000) denominam como cenas significativas. Em um segundo momento, as unidades de significado foram agrupadas em categorias temáticas mais gerais, em que se buscou captar e enunciar, descritivamente, uma versão de sentido para as vivências comunicadas (Forguieri, 1993; Amatuzzi, 1996).

\section{Resultados}

Na compreensão dos relatos analisados, duas questões ganharam evidência. Primeiramente, a experiência do adoecimento para os pacientes, e decerto para os familiares, é marcada pelo sentido de que a vida presente é muito diferente da de outrora. Há como que um choque entre o eu-corpo atual e o eu-corpo passado. Em segundo lugar, é notável a restrição pessoal que marca esta experiência do enfermo, seja em função das alterações que a pessoa sofre no corpo, seja pelas exigências e repercussões do tratamento, ou, ainda, pela maneira como se estruturam as suas relações com a família e com o meio social circundante. Tais questões estão presentes nas três categorias temáticas que foram elaboradas a partir da análise dos discursos: a experiência do paciente; 0 paciente e o outro; e a família.

4 A maior parte dos trabalhos com grupos de sala de espera relata que a intervenção é realizada no próprio local em que os pacientes aguardam pelo procedimento médico. Contudo, a área física do Ambulatório de Neurocirurgia Oncológica do HCFMRP - USP não permite esta opção. Nele, os pacientes aguardam as consultas em um longo corredor, repleto de usuários de outros diversos serviços médicos.

Psicol. Argum., Curitiba, v. 24, n. 45 p. 45-57, abr./jun. 2006. 


\section{Tabela 1}

\section{Dados dos pacientes colaboradores.}

\begin{tabular}{|l|l|l|l|l|}
\hline Nome & Idade & Diagnóstico & Tratamento* & Sintomas** $^{*}$ \\
\hline Madalena & 40 & Glioma baixo grau & Cir. & Não \\
\hline Jair & 33 & Tumor benigno & Cir., RxT & Não \\
\hline César & 70 & Glioblastoma & Cir., RxT, QT & Sim \\
\hline João Pedro**** & 72 & Meningioma & Cir., RxT, QT & Sim \\
\hline Paulo & 37 & Glioma alto grau & Cir., RxT, QT & Sim \\
\hline Aurélio & 32 & Glioma alto grau & Cir., RxT, QT & Não \\
\hline Marina & 49 & Glioma baixo grau & Cir., RxT & Não \\
\hline Jeremias & 55 & Glioblastoma & Cir., RxT, QT & Sim \\
\hline Nice & 51 & Tumor benigno & Cir. & Sim \\
\hline Joana & 39 & Pinet & Cir., RxT, QT & Sim \\
\hline Antônia & 43 & Pinealoblastoma & Cir., RxT, QT & Sim \\
\hline Cícero & 45 & Glioma baixo grau & Cir., RxT & Sim \\
\hline Lúcio & 57 & Glioma alto grau & Cir., RxT, QT & Sim \\
\hline Fábio & 32 & Glioblastoma & Cir., RxT & Sim \\
\hline
\end{tabular}

* “Cir." Refere-se à cirurgia, "RxT", à radioterapia e "QT", à quimioterapia.

** Nesta coluna, faz-se menção à presença de sintomas físicos ou neuropsiquiátricos significativos.

*** João Pedro não participou de nenhuma sessão gravada, mas seu nome figura entre os colaboradores pelo fato de sua esposa ter participado.

\section{A Ex periência dos Pacientes Manifestações iniciais da enfermidade}

Nos grupos, pacientes e familiares puderam relembrar as manifestações iniciais da doença e suas reações diante da situação que se delineava. A fala da esposa de Paulo revela uma atmosfera de urgência e choque quando da definição diagnóstica, ainda mais pelo fato de vir acompanhada pela proposta de cirurgia imediata.

Não tem um preparo, porque eles te pegam de surpresa na hora, ali [...] o médico chega ali, fala assim, olha, ele tem que fazer uma cirurgia agora, porque é grave. (Ingrid)

De uma só vez, é apresentado um diagnóstico grave e difícil de aceitar, e proposto o primeiro passo do tratamento, a cirurgia cerebral, que surge carregada de ameaças.
Sem embargo, é intenso o espanto diante da descoberta de uma doença grave, com o potencial de causar a morte. Repentinamente, a pessoa depara-se com a sua própria vulnerabilidade, como revela a fala de Aurélio:

[...] depois dos vinte e cinco anos, né, eu sempre fui uma pessoa super saudável, né. Aí, era difícil acreditar, pô, eu não pego nem gripe, agora um negócio desse! Ficava assim. Se não fosse, eu falo mesmo, abertamente, se não fosse pela ação divina mesmo, eu não suportaria não, porque, eu falo assim, eu não ia nem no médico, eu não tinha nem gripe, agora uma coisa dessa na minha cabeça...isso pode me deixar paralítico, paralisado, ou me matar, meu Deus do céu, o que é isso. (Aurélio)

Em última instância, parece que é o temor à morte que sustenta as manifestações diante da doença e do tratamento. Apesar de a morte 
A experiência vivida por pessoas com tumor cerebral e por seus familiares

não ter sido um tema abertamente trabalhado pelos participantes nos grupos, surge, veladamente, como um fator constituinte da atmosfera que envolve o paciente e seus familiares desde que a enfermidade se faz presente.

\section{0 tra ta mento}

Muitas falas, nos grupos, tinham como tema central o tratamento. Alguns participantes descreveram a sua experiência e expressaram dúvidas, expectativas e fantasias acerca das estratégias terapêuticas propostas pela equipe médica.

O período que antecede o início dos tratamentos rádio e quimioterápico é vivido com grande expectativa. Há muita preocupação e medo, sobretudo em relação aos efeitos colaterais que podem ser provocados. $\mathrm{O}$ encontro dos pacientes e de seus familiares no espaço grupal facilitou a troca de informações sobre eles. Alguns participantes externaram as suas fantasias e procuraram, junto àqueles que já haviam passado pelas terapêuticas, informações mais reais.

Para Paulo, como para a maioria dos colaboradores, a quimioterapia é o tratamento mais agressivo de todos. Assim, em vias de iniciar este tratamento, ele procurava conhecer a experiência de outros pacientes com os medicamentos.

Antônia também temia a quimioterapia. Indignada, argumentava que não vinha apresentando nenhum sintoma em função da doença, mas que poderia sentir-se mal iniciando o tratamento, o que lhe parecia paradoxal. No grupo, retomou o que ouvira dizer, em outros contextos, acerca dos efeitos negativos da medicação e dizia que, juntando tudo, sentia-se confusa.

É importante frisar, ainda, que, no período de tratamento, o hospital impõe-se como um horizonte de mundo para os pacientes e para os seus familiares, o que colabora para criarlhes uma atmosfera de restrição pessoal. Há as sessões de radioterapia, de quimioterapia e, ainda, as freqüentes visitas ao médico.

Na época do serviço, numa segunda-feira, eu estava saindo pra trabalhar, agora eu saio pra vir no médico. (Jeremias)
Portanto, desde o diagnóstico, os pacientes vêem-se às voltas com estratégias terapêuticas que provocam intensos efeitos colaterais no organismo e geram muita expectativa e dúvidas, compondo parte do cenário no qual a pessoa com tumor cerebral existe durante um certo período.

\section{Repercussões da doença e do tra ta mento}

Sobretudo, os déficits motores estão presentes na vivência dos pacientes participantes do presente trabalho. Trata-se de alterações da motricidade, que causam contrariedade e restrição ao paciente.

Eu comecei a perder...é...cair tombo; perdi essa perna aqui. Eu caía, precisa de ver. E não movimentava o dedo mais [...] Eu fui com a minha tia na cidade, eu estou andando, eu caí lá no meio do povo. (Joana)

Tais acontecimentos corporais forçam uma nova "enformação" do mundo. Contudo, muitas vezes, é com o antigo arranjo corporal que as pessoas afetadas por tais distúrbios contam, principalmente no período em que estão se adaptando às modificações.

Parece claro, ainda, o teor restritivo de todos estes prejuízos, que levam a pessoa enferma a um engajamento menos ocupado e mais passivo no mundo, e, por isso, mais distante e isolado, como notam os familiares. Além disso, sobretudo nos casos de alteração da motricidade, o paciente fica mais exposto ao risco de acidentes, 0 que 0 deixa, às vezes, frustrado, às vezes, temeroso, fundando uma atmosfera de dependência do outro, fator gerador de grande contrariedade.

É importante salientar que as repercussões causadas pelo tumor cerebral, tais como as crises convulsivas, fazem surgir nos pacientes temores e angústias que implicam em um claro movimento de restrição pessoal. Paulo, depois de sofrer uma grave convulsão, ficou receoso, com medo de ir aos mais variados lugares, com medo de atravessar as ruas. Teme deveras machucar-se em uma queda como a anterior. Sua esposa diz: 
[...] ele pegou medo, pegou trauma daquilo ali. (Ingrid)

O paciente apresenta um relato esclarecedor acerca das suas ansiedades:

[...] eu vou tomar um banho, não posso trancar a porta. Como eu tenho filhas mulheres, uma de quinze e outra de doze, a rapinha do tacho é pequenininha, tudo mulher, se precisar me dar socorro, vai ser mulher. Eu não devo tomar banho nu, né, totalmente nu. Então, por aí vocês tem uma noção.

Nice apresenta um discurso semelhante. Depois de passar por uma cirurgia, sofrera com tonturas e prejuízos no equilíbrio corporal. Por isso, temia deslocar-se sozinha pelas ruas. Isto restringiu as suas possibilidades e aumentou a dependência em relação a outras pessoas.

\section{0 eu-corpo a tual e o eu-corpo passado}

César trabalhou durante muito tempo na roça, era habituado aos esforços exigidos pela sua atividade. Mais recentemente, levantava-se cedo para auxiliar o filho em um serviço de transporte escolar. Ao voltar para casa, pegava sua bicicleta e dirigia-se ao centro da cidade para acertar pequenas pendências. Hoje, diante dos prejuízos motores e cognitivos que vivencia, diz-se inútil, ainda mais por depender dos cuidados de sua esposa. Sofia, acompanhante de César, diz:

[...] pra ele aceitar o que [...] era e o que está agora é difícil, a gente tem que reconhecer isso. (Sofia)

Os relatos de Nice também revelam repercussões emocionais profundas diante dos prejuízos que sofrera em seu corpo. Segundo a paciente, a enfermidade não a preocupa mais. Ela delimitou, então, o foco das suas contrariedades:

O problema meu, que eu fico muito nervosa, é a seqüela que eu fiquei da operação. Fiquei com uma paralisia facial e deu problema no meu olho. O meu olho é a pior coisa. (Nice)
Além disso, Nice convive com um déficit leve da marcha. $O$ fato é que a sua fala está perpassada pelo sentido de que, em sua vida, há um antes - "quando eu tinha saúde" - e um agora, marcado por alterações físicas e modificações em sua própria identidade. São o eu-corpo passado e o eu-corpo atual em conflito.

[...] a gente mudou, né, muito, não é mais a mesma pessoa, né. Você muda muito. (Nice)

Nice, em sua fala, volta-se para o passado pessoal e percebe o quanto era ativa e autônoma antes do adoecimento.

E eu que era uma pessoa acostumada a sair, comprar de tudo pra casa, ia no banco, ia em todo lugar, ia e voltava e agora não vou por causa disso. Não vou. Eu ando, assim, um pouco, devagar, assim eu vou...Porque a gente fica muito dependente dos outros. Sempre uma pessoa junto, uma pessoa junto, a gente que não era acostumada, a gente primeiro se irrita com isso, né. (Nice)

Em sua experiência atual, Nice ressente-se em virtude das suas limitações, pelo fato de habitar um corpo que atualmente não lhe permite realizar as mesmas atividades de outrora nem com a mesma habilidade. Ressentese também por precisar de ajuda para realizar muitas das tarefas cotidianas. Para contrabalançar a sua insatisfação, costuma ir a lugares próximos da sua casa, pois assim sente-se segura em ir sozinha e recupera algum sentido de autonomia.

Os relatos da paciente revelam o quão conflituoso é o seu enfrentamento das seqüelas do tumor cerebral. Suas vivências atuais envolvem o convívio com privações e com a diminuição dos seus recursos corporais, o que gera muita insatisfação, cerceamento e isolamento.

Nesta direção, pode-se dizer que é em tempos passados que os pacientes localizam o vigor, a capacidade para o trabalho, para os deslocamentos livres de quaisquer impedimentos e a possibilidade de lançar-se nas atividades diárias. Localizam as mudanças, sobretudo, no corpo: é o equilíbrio que não é mais o mesmo, a agilidade que não é como a de antes. 


\section{O Paciente e o Outro}

Nesta categoria, destacam-se as relações que se estabelecem entre os pacientes e os seus familiares, e entre os pacientes e o seu meio social circundante. De modo geral, pode-se dizer que a relação com o outro é mais um setor da experiência dos enfermos, colaboradores na pesquisa, em que se delineiam formas de estreitamento das possibilidades pessoais.

\section{Superproteçã o, cercea mento e irrita çã o}

Um aspecto significativo dos relatos está ligado a comentários e atitudes reveladores de uma dinâmica de superproteção que se instalara nas relações entre alguns familiares e pacientes. César queixa-se pelo fato de sua esposa, Angélica, não o deixar à vontade um instante sequer.

Ele levanta à noite, vai ao banheiro, mas eu falo pra ele: "me chama, me chama". Às vezes, eu acordo; quando ele bate a mão na porta, eu já: "Aonde você vai"? “Vou lá no banheiro". [...] Então, eu levanto e vou levar ele e volto com ele, porque se deixar ele cai. (Angélica)

Fica claro que os passos dos pacientes são seguidos de perto. Aos com melhores condições físicas e cognitivas, como Jeremias, não é fácil convencer a família a deixá-lo realizar suas tarefas ou passeios sem companhia. Jeremias percebe que seus familiares, desde a esposa até sua neta pequena, temem que se perca na rua e, por isso, controlam seus movimentos.

Estou na esquina, o outro já está lá: ô, vem embora. Eu falei: pára com isso, uai. (Jeremias)

Silvia, esposa do paciente, conta que, quando o companheiro dorme durante muito tempo, sua preocupação torna-se tão intolerável que ela agita-o, buscando verificar se ele ainda vive.

Com efeito, é com contrariedade e irritação que os pacientes percebem esta atmosfera de cuidado e medo. A insegurança e a dificuldade dos cuidadores para se afastar criam nos enfermos a impressão de estarem sendo vigiados. Sentem- se invadidos, tolhidos e diminuídos em suas capacidades ou em sua condição geral de saúde.

[...] a minha filha [...] ela não separa de mim um segundo. Às vezes eu fico até brava com ela. Acaba de ir pra casa dela, acho que nem bem chega lá, já está voltando. (Joana)

A necessidade de cuidados por parte do paciente, sobretudo nos casos de maiores impedimentos motores e cognitivos, configura uma relação de dependência entre o enfermo e os seus cuidadores. Trata-se de um fator restritivo e que deflagra reações, como a busca impetuosa por autonomia, muitas vezes até de maneira desorganizada, um sentimento de inutilidade, a idéia de constituir um embaraço para os familiares e muita irritação e descontentamento.

[...] ele falou, assim, pra mim, que ele está "enchendo" aqui já. (Angélica, esposa de César)

Neste campo marcado pela superproteção e pela dependência, a relação de cuidado, em alguns casos, incorpora um tom de infantilização do paciente. Deste modo, alguns trechos das falas de familiares chegam a lembrar a forma de dispensar cuidados às crianças. Neste contexto, o que poderiam ser consideradas conquistas dos pacientes ganham a conotação de peripécias.

\section{O Outro}

Alguns dos colaboradores mencionaram, ainda, a forma como vivenciam a aproximação com o seu meio-social extrafamiliar. De um modo geral, pode-se dizer que as pessoas são vistas como um obstáculo difícil de enfrentar para os pacientes, ainda mais quando elas ofendem ou perturbam de alguma maneira direta.

Eu fui na casa de uma conhecida nossa fazer um terço pra uma outra pessoa que estava doente [...] A hora que eu passei na porta da casa, tinha dois rapazes e eu fui sem a touquinha. [...] Estava calor. E o cabelo estava crescendo um pouquinho e eu falei, eu vou sem a touquinha. A hora que eu passei na porta, tinha dois rapazes. Um olhou pro outro e falou assim: "está na 
moda"? Aquilo me doeu tanto. Deu vontade de voltar pra traz e contar tudo que eu passei, contar porque que eu estava assim, que não era moda. (Antônia)

Cícero, de forma um pouco mais vaga, falou da vergonha que sentiu quando vivenciou um episódio convulsivo em um bar repleto de pessoas. E emendou:

Aí, depois que eu operei, também nunca mais voltei, assim, no meio de gente, em lugar nenhum. Aonde eu entro no meio de gente é aqui [no hospital]. (Cícero)

Assim, parece que, para o paciente, pode haver vários fatores negativos ligados à presença do outro. Uma palavra negativa, que diminui as esperanças, o desafio de mostrar-se ao outro com o corpo modificado, as fantasias sobre o que as pessoas pensam e falam acerca do tumor cerebral e do tratamento, o preconceito, são fatores difíceis de tolerar, para o enfermo, e que acabam levando-o a um certo isolamento social.

\section{A Fa mília}

Vários discursos deixam transparecer 0 compromisso do familiar com o bem-estar do ente enfermo. Entrementes, este cuidado, baseado em compromisso e sensibilidade, exercido pelo familiar da pessoa com tumor cerebral, é o mesmo cuidado que desliza para a proteção que restringe o paciente e o mesmo cuidado que acarreta grande desgaste ao próprio cuidador. $\quad \mathrm{Da}$ parte dos familiares, o ambiente de proteção, tido por alguns pacientes como rigidamente construído, guarda uma imensa carga de preocupações, temores, responsabilidades para com o outro e vontade de servir como ponto de apoio e de estímulos. De certa forma, todo o esforço para cuidar dos enfermos é uma das faces da vivência dos familiares, que é também marcada por sofrimento emocional e desassossego. Silvia e Angélica, esposas de Jeremias e de César, respectivamente, reconhecem que suas atitudes de proteção excessiva, por vezes, contribuem para o aborrecimento de seus maridos. Contudo, mostram que agem movidas pelo temor de que seus companheiros sofram um malestar repentino, como uma crise convulsiva, por exemplo, ou que sofram um acidente causado pelas disfunções motoras com as quais convivem. O discurso do familiar também é marcado pelo sentido de que sua vida sofreu intensas mudanças a partir do adoecimento do ente próximo. As transformações incluem o afastamento do trabalho e o distanciamento em relação a alguns prazeres, tais como festas e viagens.

É, muda tudo [...] nossa senhora. Três anos pra cá, parou as festas, acabou tudo, tudo. Acaba tudo. (Roberta, esposa de João Pedro) As falas parecem expressar abdicação, renúncia e, também, resignação.

Além disso, a situação de adoecimento por tumor cerebral força modificações na dinâmica familiar. Neste ponto, a experiência de Lúcio é ilustrativa. No seu entender, sua esposa transformou-se no "homem da casa", pois é ela quem exerce uma ocupação fora do lar e mantém financeiramente a família. Há algum tempo, Lúcio cuidava ao menos das tarefas domésticas, mas, frustrado, comentou no grupo que, mesmo este pouco, hoje ele não consegue realizar a contento.

Frente às exigências da relação de cuidado, das preocupações e mudanças no ritmo vital, os familiares também apresentam sinais de desgaste físico e emocional. $\mathrm{O}$ contato direto com 0 ente enfermo é cansativo, bem como a rotina de tratamento no hospital. Roberta falou das dificuldades para cuidar do esposo, João Pedro, dependente do seu zelo em grau elevado:

Já andando é uma grande coisa, né, de estar acompanhando. O meu marido [...] preciso levar ele no banheiro, trazer, você dá banho, faz barba, você corta o cabelo, você faz tudo. É mesma coisa que uma criancinha de 5 meses, você tem que fazer tudo [...] Às vezes, eu vou querer fazer ele andar sozinho, ele anda, mas fico sempre pertinho dele. Na hora que ele dá uma passeadinha, estou sempre encostada nele...não descuido. (Roberta)

Além dos cuidados diretos ao paciente, há outras solicitações, como as mais variadas demandas domésticas e familiares que continuam a ser atendidas.

O esgotamento, em certas circunstâncias, leva o familiar a um comportamento impaciente diante do companheiro doente. Eliane, por exemplo, jactava-se, em uma das sessões, pelo fato de trabalhar fora de casa todos os dias, o que a obri- 
ga a afastar-se do contato com o marido, que, segundo ela, vinha apresentando atitudes irritadiças e nervosas.

\section{Discussã o}

Realizou-se, a partir de uma perspectiva compreensiva em psicologia, uma aproximação à experiência vivida por pessoas com tumores cerebrais e por seus familiares que participaram de sessões de grupo de sala de espera em um ambulatório médico especializado em neurocirurgia oncológica. Esta aproximação revelou o severo impacto que a enfermidade representa na vida dos colaboradores do estudo. Destacaram-se, sobremaneira, as restrições pessoais vividas pelos pacientes e a sua dificuldade em integrar a experiência atual com a de outrora.

Lepola (2001) sublinhou o fato de que, desde as fases iniciais do adoecimento por tumor cerebral, o enfermo lida com significativas transformações em suas capacidades corporais. O rompimento com a vivência corporal de outrora implica na ruptura com a vida cotidiana de outrora, na ruptura com a maneira com que a pessoa se entregava às tarefas e demandas da vida social, familiar e ocupacional. Inicialmente, há o choque diante dos déficits, sobretudo os da linguagem e os da motricidade. Depois, com o avanço do tratamento, surge a desilusão diante da cronicidade da doença e das disfunções por ela desencadeadas. Além disso, a melhora é incerta e os pacientes convivem com o medo da recorrência do tumor (Leavitt et al., 1996).

Com efeito, as alterações na motricidade e na linguagem, o risco de convulsões, bem como as mudanças na esfera cognitiva do enfermo favorecem o estabelecimento de uma relação de dependência com os seus cuidadores. Assim, desenvolve-se, no paciente, um forte senso de incompetência e de quebra das liberdades pessoais. Daí 0 empenho, da sua parte, em manter atividades sociais e ocupacionais, sobretudo as que ele exercia antes de adoecer. Com isso, preservam-se aspectos relevantes da identidade pessoal e atenuam-se as relações de dependência, que tanta contrariedade trazem ao paciente (Fox \& Lantz, 1998; Wideheim et al., 2002).

Contudo, todo este empenho pode ser prejudicado por outra dimensão, afetada nos portadores de tumor cerebral: trata-se da relação com os outros. O estudo realizado por Fox e Lantz (1998) também destaca o estigma vivenciado pelos pacientes, que se sentem humilhados e discriminados em função dos déficits que podem apresentar e, com isso, isolam-se socialmente.

Os mesmos autores comentam que o comprometimento das capacidades físicas e mentais do enfermo, devido ao tumor cerebral, representa um severo ataque à sua identidade pessoal e oferece grandes dificuldades na tarefa de integrar a sua condição anterior à enfermidade com a atual. Volta-se a discutir, portanto, a idéia de um conflito entre o eu-corpo atual e o eu-corpo passado na experiência do paciente.

Merleau-Ponty (1999) mostrou que a significação total da vida muda na privação orgânica e que a pessoa com tumor cerebral é lançada em uma experiência que a transporta a uma nova "estrutura de conjunto" existencial, marcada, sobretudo, pelas restrições que ela passa a vivenciar no contato com as coisas e com os outros. Estas duas experiências, a anterior à doença e a presente, não se unem completamente. Prova disso é o conflito entre o eu-corpo atual e o eu-corpo passado. A necessidade de reabrir um passado em que não havia perdas orgânicas que limitassem a existência é um exemplo significativo de atitude existencial diante da doença. Dessa forma, o enfermo busca desviar-se das regiões do seu corpo ou de aspectos da sua vida que o impedem de aderir plenamente ao mundo e aos projetos que nele surgem.

Neste contexto, qualquer estratégia de recusa da deficiência pode ser compreendida como um empenho do indivíduo para manter-se aberto àquilo que o corpo fazia antes que surgisse o déficit, um esforço para conservar o campo prático que se tinha antes do acontecimento orgânico limitante. A evitação dos espaços sociais, por parte dos pacientes, também pode ser compreendida como um movimento de recusa da doença ou dos déficits a ela associados. Tais espaços configuramse como locus privilegiados para o desocultamento das suas deficiências, na medida em que o outro interroga o corpo doente do paciente, seja de modo fantasiado, na expectativa angustiada do enfermo, seja de maneira real.

Quanto aos familiares dos pacientes, permanece válida a idéia de que o adoecimento de um dos membros do núcleo de parentes possui um caráter desagregador para todo o grupo. Pode- 
se dizer que a saúde da família sofre profundas alterações (Kristjanson \& Ashcroft, 1994). Além disso, a sua dinâmica sofre transformações. Há a necessidade de mudanças nos papéis familiares e desenvolvem-se novas relações de cuidado uns com os outros, mas, sobretudo, com o membro enfermo (Wideheim et al., 2002). São estas relações que podem se encaminhar para atitudes superprotetoras para com o doente, conforme o que foi destacado no presente estudo.

Por fim, são possíveis algumas considerações acerca das contribuições e questões suscitadas pela presente pesquisa. Primeiramente, sublinha-se o fato de que as compreensões aqui elaboradas apresentam-se em sintonia com aquilo que outros estudos explicitaram sobre a experiência de portadores de tumor cerebral, bem como a de seus familiares. A literatura sobre os aspectos vivenciais no campo da neuro-oncologia, tanto quanto o produto da presente investigação, evidenciam a multiplicidade dos obstáculos enfrentados pelos enfermos e por seus acompanhantes, reafirmando a relevância do cuidado interdisciplinar a eles. Quanto aos grupos de sala de espera, estratégia de apoio psicossocial que carece de maiores estudos, revelaram-se um espaço rico e seguro para a expressão e manejo das dificuldades que pacientes e familiares vivenciam no cotidiano. A situação grupal foi favorável, ainda, para que a experiência comunicada daqueles que vivenciam a situação pesquisada fosse acessada. 